\title{
Establishment and characterization of a novel human cholangiocarcinoma cell line with high metastatic activity
}

\author{
KWUNTIDA UTHAISAR ${ }^{1,3,7}$, KULTHIDA VAETEEWOOTTACHARN ${ }^{1,3}$, WUNCHANA SEUBWAI ${ }^{2,3}$, \\ CHUTIMA TALABNIN ${ }^{4}$, KANLAYANEE SAWANYAWISUTH ${ }^{1,3}$, SUMALEE OBCHOEI $^{1,3}$, \\ RATTHAPHOL KRAIKLANG $^{5}$, SEIJI OKADA ${ }^{6}$ and SOPIT WONGKHAM ${ }^{1}$ \\ ${ }^{1}$ Department of Biochemistry, ${ }^{2}$ Department of Forensic Medicine, Faculty of Medicine, and \\ ${ }^{3}$ Liver Fluke and Cholangiocarcinoma Research Center, Khon Kaen University, Khon Kaen 40002; \\ ${ }^{4}$ School of Biochemistry, Institute of Science, Suranaree University of Technology, Nakhon Ratchasima 30000; \\ ${ }^{5}$ Department of Nutrition, Faculty of Public Health, Khon Kaen University, Khon Kaen 40002, Thailand; \\ ${ }^{6}$ Division of Hematopoiesis, Center for AIDS Research, Kumamoto University, Honjo, Kumamoto 860-0811, Japan
}

Received March 18, 2016; Accepted May 11, 2016

DOI: $10.3892 /$ or.2016.4974

\begin{abstract}
Cholangiocarcinoma (CCA) is a highly metastatic tumor, and the lung is a common site of metastasis. A greater understanding of the biology of metastases is needed to improve treatment outcomes. Herein, a highly metastatic human CCA subline, KKU-213L5 from an original cell line, KKU-213 that has marginally metastatic ability, was established and characterized. KKU-213L5 was selected in vivo through the fifth serial passage of pulmonary metastasized tissues via tail-vein injection in NOD/scid/Jak3 mice. The metastatic abilities of the KKU-213L5 cells were compared with the parental line in vitro and in vivo. The expression profile of this metastatic cell line was determined using real-time PCR. KKU-213L5 cells were found to possess higher metastatic phenotypes, i.e., growth rates, stem cell surface markers (CD133), migration and invasion characteristics when compared with the parental cells. Compared to the KKU-213 cells, KKU-213L5 cells formed larger tumors in subcutaneous xenografted mice and had a $>10$-fold increase in lung metastases in the tail-vein
\end{abstract}

Correspondence to: Professor Sopit Wongkham, Department of Biochemistry, Faculty of Medicine, Khon Kaen University, 123 Mitraparb Road, Muang, Khon Kaen 40002, Thailand E-mail: sopit@kku.ac.th

Professor Seiji Okada, Division of Hematopoiesis, Center for AIDS Research, Kumamoto University, Honjo, Kumamoto 860-0811, Japan E-mail: okadas@kumamoto-u.ac.jp

Present address: ${ }^{7}$ Department of Medical Technology, School of Allied Health Sciences and Public Health, Walailak University, Nakhon Si Thammarat 80160, Thailand

Key words: cholangiocarcinoma, bile duct cancer, metastasis, AGR2, KiSS-1, metastasis-associated genes, metastatic mouse model, cell line injected metastatic mouse model. Mice injected intravenously with KKU-213L5 cells had a significantly shorter survival. Analysis of the expressed genes related to progression of cancer revealed significant upregulation of anterior gradient protein-2 (AGR2) and suppression of KiSS-1 in the KKU-213L5 cells. The association of these two genes with metastasis was affirmed in CCA patient tissues since increased AGR2 expression and decreased KiSS-1 expression were found in higher stage patient tumors. In conclusion, a highly metastatic human CCA cell line was established and characterized. It is plausible that the differential expression between the parental KKU-213 and highly metastatic KKU-213L5 cells may be beneficial to classify novel genes associated with metastasis. The KKU-213L5 cell line should serve as a valued device for discovering the molecular mechanisms of CCA metastasis and enabling the search for an effective therapy for the unmet clinical need in CCA.

\section{Introduction}

Metastasis is the most detrimental feature of cancer that leads to patient mortality. It is a highly selective process which is comprised of a number of complex and interrelated steps. Cancer cells must escape from the primary tumor site, survive in the circulation, invade multiple distant tissues or organs and finally inhabit specific organ sites $(1,2)$. Cancer cells in primary and metastatic tumors exhibit differences in biological heterogeneity that raise difficulty for the treatment of metastatic tumors. Understanding the cellular and molecular pathogenesis of metastasis is important to prevent metastasis and to search for an effective therapy for metastatic cancers.

Cholangiocarcinoma (CCA) is a highly invasive tumor that leads to an extremely poor prognosis. As CCA is difficult to diagnose at the early stage, the vast majority of CCA patients are diagnosed when the disease has progressed to the metastatic stage. The common sites of metastasis are the liver, lymph nodes, lung and bone (3-6). Metastasis is usually the cause of death of CCA patients. Current treatments e.g., radio- 
therapy, chemotherapy and surgery do not effectively ensure or prolong patient survival (7).

At present, the understanding of the metastatic process of CCA at the molecular level is limited. Experimental systems that mimic endogenous contributing factors are required to understand the complexity of metastasis. Most of the CCA cell lines used rarely develop tumors that metastasize, making it difficult to study these detrimental events in cancer progression. To understand the molecular mechanism of metastasis in CCA, a highly metastatic CCA cell line is needed. This cell line can then be used to investigate the causes of metastasis while at the same time test for new therapies. Moreover, the molecular networks and signaling pathways between individual molecules and metastasis can be elucidated.

In the present study, an in vivo selection resulted in the establishment of a human CCA cell subline, KKU-213L5, which possesses higher metastatic behaviors, i.e., growth rate, stem cell marker characteristics, migration and invasion abilities, than those of the parental, KKU-213 cells. The aggressiveness of KKU-213L5 compared to the parental cells was demonstrated in the subcutaneous xenograft and tail vein injected lung metastasis mouse models. Expression levels of various molecules with regard to the metastatic processes were compared. Finally, two genes, anterior gradient protein-2 (AGR2) and KiSS-1, were identified in the KKU-213L5 cell line and their associations with metastasis in CCA patients were validated. This newly established subline should be of benefit not only to basic investigations but also to translational research efforts on the metastasis of CCA and of cancer as a whole.

\section{Materials and methods}

Cell lines and CCA patient tissues. The parental CCA cell line, KKU-213, was established from the primary tumor of a Thai male with histologically confirmed CCA as previously described (8). The presence of liver fluke Opisthorchis viverrini eggs was noted in this pathological record. The cell line KKU-213 (JCRB1557) was purchased from the Japanese Collection of Research Bioresources (JCBR) Cell Bank, Osaka, Japan.

Paraffin-embedded histologically confirmed CCA tissues $(n=32)$ were obtained from the specimen bank of the Liver Fluke and Cholangiocarcinoma Research Center, Faculty of Medicine, Khon Kaen University, Thailand. The protocol was reviewed and approved by The Khon Kaen University Ethics Committee for Human Research (HE571464) based on the Declaration of Helsinki and ICH-Good Clinical Practice Guidelines.

Establishment of a highly metastatic KKU-213L5 subline. A highly metastatic subline namely, KKU-213L5, was established from the metastasized lung tissues of NOD/scid/Jak3 mice (NOJ mice) (9). Mice were accommodated and monitored according to institutional guidelines. The Institutional Animal Care and Use Committee of Kumamoto University approved the experimental procedures.

The parental cells, KKU-213 (5x10 5 cells), were inoculated through tail veins of the 8 - to 10 -week old male NOJ mice. Approximately 18 days after injection, the mice were sacrificed and the pulmonary metastatic tumors were resected and minced for in vitro culture. The cells were re-passaged and cultured until the absence of fibroblasts occurred. Then, cultured metastatic tumor cells were inoculated into the naïve mice in the same manner. After repeating these in vivo selection procedures 5 times, the cells which preferentially metastasized to the lungs following intravenous injection were obtained and designated as KKU-213L5 (lung metastatic variant 5).

KKU-213 and KKU-213L5 cells were cultured in Ham's F-12 media supplemented with $10 \%$ heated inactivated fetal bovine serum (FBS), $100 \mathrm{U} / \mathrm{ml}$ of penicillin $\mathrm{G}$ and $100 \mu \mathrm{g} /$ $\mathrm{ml}$ streptomycin. Cells were incubated at $37^{\circ} \mathrm{C}$ in a $5 \% \mathrm{CO}_{2}$ incubator.

Cell proliferation and clonogenic assays. Cell proliferation was determined using the dye exclusion method. Briefly, exponentially growing cells $\left(5 \times 10^{3}\right.$ cells/well) were plated into a 24-well plate. Every other day, the cells were trypsinized and viable cells were determined by trypan blue staining. Doubling times of each cell line were calculated as described by Patterson (10).

Survival and proliferative activities were determined using a clonogenic assay (11). Briefly, 200 cells in Ham's F-12 with $10 \%$ FBS were seeded in 6-well plates and incubated in a 5\% $\mathrm{CO}_{2}$ incubator at $37^{\circ} \mathrm{C}$ for 7 days. Colonies were fixed in $4 \%$ $\mathrm{v} / \mathrm{v}$ paraformaldehyde, stained with $0.5 \% \mathrm{w} / \mathrm{v}$ crystal violet and counted.

Cell surface marker determination. The expression levels of cell surface markers were determined by flow cytometric analyses with phycoerythrin (PE)-conjugated anti-CD29 (TS2/16; BioLegend, San Diego, CA, USA), allophycocyanin (APC)-conjugated anti-CD34 (AC136; Miltenyi Biotec, Teterow, Germany), fluoresecein isothiocyanate-conjugated (FITC) anti-CD44 (IM7), Alexa Fluor ${ }^{\circledR}$ 647-conjugated anti-CD90 (F15-42-1), APC-conjugated anti-CD117 (104D2) (all from BioLegend) and PE-conjugated anti-CD133 (AC133; Miltenyi Biotec). Single-cell suspensions of $\sim 1 \times 10^{6}$ cells were prepared in phosphate-buffered saline (PBS) containing 3\% FBS and $0.05 \%$ sodium azide. After staining with each antibody and incubation for $30 \mathrm{~min}$ on ice, the cells were washed twice with PBS and analyzed on an LSR II flow cytometer (BD Biosciences, San Jose, CA, USA). The expression levels of each surface marker were analyzed from at least 20,000 cells using FlowJo software (Tree Star, San Carlos, CA, USA) and presented as a percentage of positive cells. Isotype-matched antibodies were used as controls.

Wound healing assay. Cells were seeded into a 12-well plate and incubated overnight in complete media. A sterile 200- $\mu 1$ pipette tip was used to create a scratch wound on the monolayer of cells and the detached cells were removed. Cells were then incubated further in $1 \%$ FBS media, and images were captured at $6,12,18$ and $24 \mathrm{~h}$. The migrating distance was measured as the relative distance of cell migration measured from 0 time as previously described (12).

In vitro cell migration and invasion assays. The migration and Matrigel cell invasion assays were performed as previously described (12). Briefly, polycarbonate membranes with $8-\mu \mathrm{m}$ 
pores were coated with $0.5 \mathrm{mg} / \mathrm{ml}$ Matrigel (BD Biosciences) and allowed to stand overnight. The membranes were rehydrated and $1.2 \times 10^{4}$ of CCA cells were placed onto the upper chamber of a Transwell unit. Ham's F-12 media with $10 \%$ FBS was used as a chemoattractant in the bottom chamber. After $18 \mathrm{~h}, 4 \%$ paraformaldehyde was added to fix the migrated or invaded cells before the cells were stained with $0.4 \%$ sulforhodamine $\mathrm{B}$. The membranes were dried and the numbers of migrated/invaded cells from $9 \times$ low power fields (magnification, x100) were counted. Mean values were determined from triplicated assays. At least two independent experiments were performed.

Tumor growth assay in xenografted mice. KKU-213 or KKU-213L5 cells ( $1 \times 10^{6}$ cells) were subcutaneously injected in each flank side of the 8- to 10-week old male BALB/c Rag-2-/ $\mathrm{Jak}^{-/-}$mice $(\mathrm{n}=8)$. Tumor volumes were measured using a vernier every 3 days. Tumors were removed and weighed at 12 days post-injection.

Pulmonary metastasis assay in vivo. NOJ mice aged 8-10 weeks were used to estimate the in vivo metastatic potential to the lung. KKU-213 or KKU-213L5 cells ( $5 \times 10^{5}$ cells/mouse) were intravenously inoculated in mice via the tail vein. Lungs were removed on days 13 and 21 after inoculation, and fixed in 4\% paraformladehyde overnight for histochemical study. The total number of lung micrometastases and macrometastases were microscopically evaluated. Cell clusters with a diameter $<100 \mu \mathrm{m}$ were defined as micrometastases and those of diameter $>100 \mu \mathrm{m}$ were defined as macrometastases. For survival analysis, the survival of mice was observed until 40 days.

Histological evaluations. The paraffin sections were prepared for histological study according to the standard protocol. The sections were stained with hematoxylin and eosin, or CK19 antibody for immunohistochemistry. For CK19-immunohistochemistry, tissue sections were incubated with anti-KRT19 (HPA002465; Sigma-Aldrich, St. Louis, MO, USA) at $4^{\circ} \mathrm{C}$ overnight followed by biotinylated goat anti-rabbit IgG (Vector Laboratories, Burlingame, CA, USA) at room temperature for $30 \mathrm{~min}$. Signals were enhanced using the Vectastain Elite ABC standard kit (Vector Laboratories) and detection was performed using the Histofine ${ }^{\circledR}$ DAB substrate kit (Nichirei Biosciences, Inc., Tokyo, Japan).

AGR2 and KiSS-1 immunohistochemistry was performed in 32 intrahepatic mass-forming CCA patient tissues using 1:500 rabbit polyclonal anti-AGR2 antibody (Abcam, Cambridge, MA, USA) and 1:50 rabbit polyclonal anti-KiSS-1 antibody (Santa Cruz Biotechnology, Dallas, TX, USA) at room temperature, overnight. Anti-rabbit IgG EnVison (Dako, Carpinteria, CA, USA) was used as the secondary antibody. The percentage of positive cells was scored as follows: $0 \%$, negative; $1-25 \%,+1$; $26-50 \%,+2$; and $>50 \%,+3$; and the intensity of the staining as follows: weak, 1; moderate, 2 ; and strong, 3. The expression levels of AGR2 and KiSS-1 were semi-quantitatively determined using an immunohistochemistry (IHC) index equal to the percentage of positive cells $\mathrm{x}$ intensity.

Real-time RT-PCR array. A real-time PCR array of 79 genes including 77 metastatic-associated genes and two internal control genes $\left[\beta\right.$-actin and $\beta_{2}$ microglobuli $\left.\left(\mathrm{B}_{2} \mathrm{M}\right)\right]$ was set (Table I). The metastatic-associated genes were selected from the literature review, a commercial metastatic PCR array, and the 'Epithelial mesenchymal transition gene signatures in cancer drug discovery, diagnostics and treatment' (13). The primer sequences were designed using Vector NTI (Thermo Fisher Scientific, Waltham, MA, USA).

TRIzol reagent (Invitrogen, Carlsbad, CA, USA) was used to extract total RNA from cells, and reverse transcription of total RNA ( $2 \mu \mathrm{g})$ was performed using High Capacity cDNA Reverse Transcription kits (Applied Biosystems, Foster City, CA, USA). Quantitative real-time PCR, the PCR protocol and data analysis were as described by Uthaisar et al (12). $\beta_{2} \mathrm{M}$ was used as an internal control.

Statistical analysis. Data were analyzed using SPSS 16.0 Windows Evaluation software (SPSS, Inc., Chicago, IL, USA). Quantitative data are expressed as mean \pm SD. Student's t-test was used for comparison between two groups. A P-value of $<0.05$ was considered to indicate a statistically significant result.

\section{Results}

Properties of the highly metastatic subline KKU-213L5 in vitro

Morphology and growth properties of the cultured cells. The culture appearance of the established KKU-213L5 cell subline and the parental KKU-213 cell line as determined by phase contrast microscopy demonstrated considerably similar epithelial morphology with a polygonal shape, and large nuclei (Fig. 1A). The growth rate of the KKU-213L5 subline exceeded that of the parental KKU-213 cells (Fig. 1B). The average doubling time for KKU-213 was $23.4 \mathrm{~h}$ and that for the metastatic KKU-213L5 was $20.3 \mathrm{~h}$. The clonogenic assay that represents survival and proliferative activities revealed that KKU-213L5 cells had a significantly higher colony forming capability than that of the KKU-213 cells (Fig. 1C).

Migration and invasion activities. Migration and invasion are the most important phenotypic characteristics of cancer metastasis. To examine the ability of migration, cell scratching assays were performed and compared between the KKU-213 and KKU-213L5 cells. Following incubation of physically wounded cells at indicated time points, the relative migrating distance of KKU-213L5 was significantly longer than that of KKU-213 ( $\mathrm{P}<0.001$; Fig. 2A). The migration activities using Boyden chamber assays demonstrated that KKU-213L5 cells had a $\sim 5$-fold higher migration ability than the parental line $(\mathrm{P}<0.01)$ (Fig. 2B). The number of migrated cells observed was $521 \pm 87$ for KKU-213L5 and 104 \pm 11 for KKU-213.

Invasion is a crucial step in metastasis; the invasion ability of the KKU-213L5 cells was compared to that of KKU-213 cells using the Matrigel invasion assay. As shown in Fig. 2C, KKU-213L5 had an aggressive capacity to invade the matrix compared to the parental cells $(\mathrm{P}<0.001)$. The number of invaded cells for KKU-213L5 was $188 \pm 9$ and for KKU-213 the number was $120 \pm 8$.

Differential expression of stem cell markers. Emerging roles of cancer stem cells (CSCs) in tumorigenesis, growth and 
A
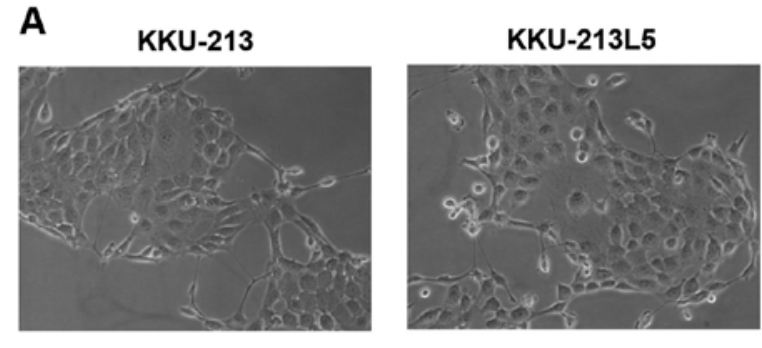

C

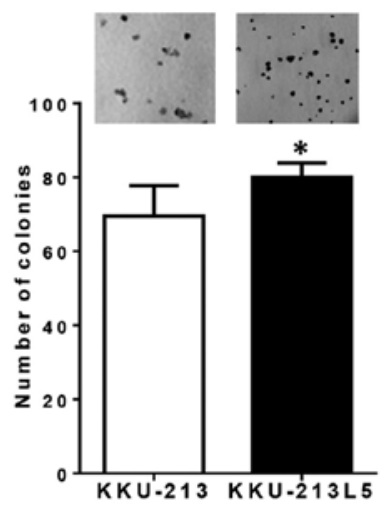

B

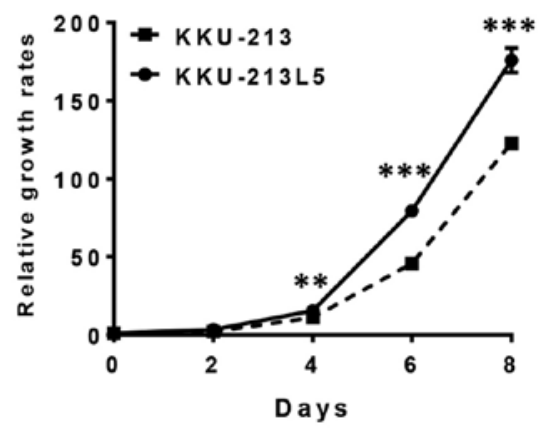

$\mathbf{D}$

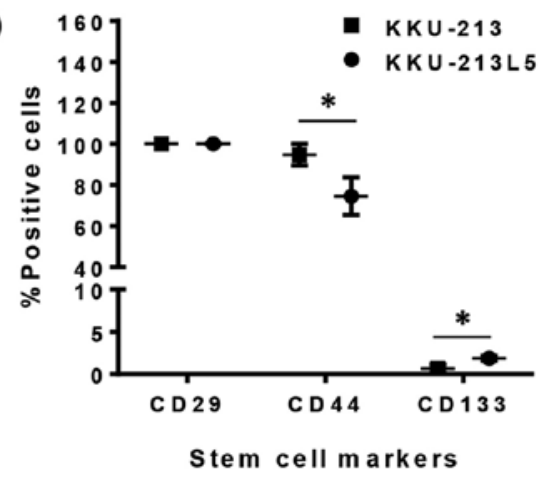

Figure 1. Characteristics of the KKU-213 and KKU-213L5 cells. (A) Cell morphology, (B) the proliferative potential as determined by dye exclusion, (C) colony formation assays, and (D) surface marker expression were compared between the KKU-213 and KKU-213L5 cells. The data are shown as mean \pm SD from triplicate assays of one of two independent experiments for proliferation and colony formation assays; and from 3 independent experiments for surface marker expression; ${ }^{*} \mathrm{P}<0.05,{ }^{* *} \mathrm{P}<0.01,{ }^{* * *} \mathrm{P}<0.001$.

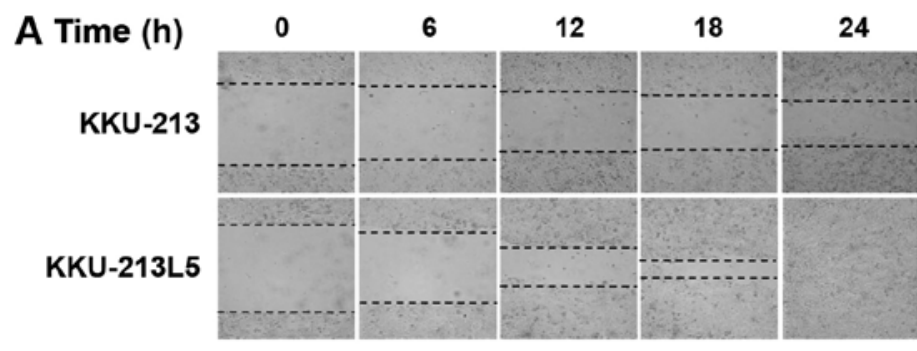

B

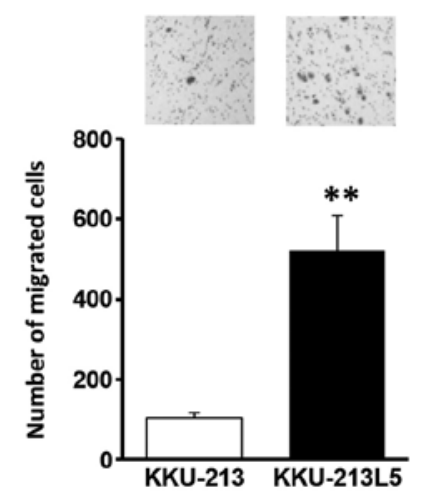

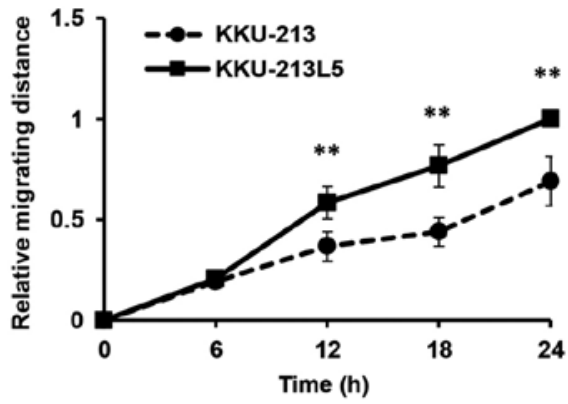

C
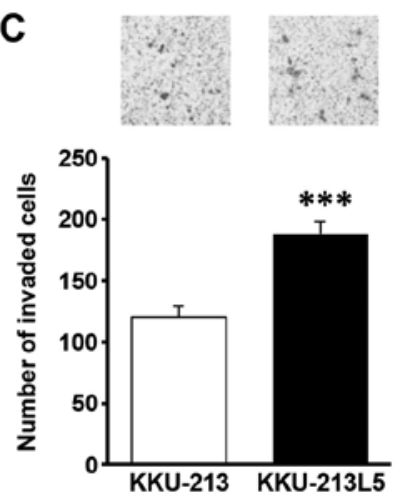

Figure 2. Cell migration and invasion. Cell migration of the KKU-213 and KKU-213L5 cells was compared using (A) wound healing and (B) Boyden chamber assays. (C) Invasion activity was determined using Matrigel-coated Boyden chambers. Images from 9 fields/condition were captured under a magnification of $\mathrm{x} 100$ and cell numbers were counted. All data are mean $\pm \mathrm{SD}$ of triplicate assays and represent one of two independent experiments; ${ }^{* *} \mathrm{P}<0.01,{ }^{* * *} \mathrm{P}<0.001$.

metastasis have been recognized (14). The high plasticity and stress-resistant phenotypes of CSCs make them potential candidates for metastatic cells. It was speculated that the in vivo selection of KKU-213 cells may preferentially select 
A

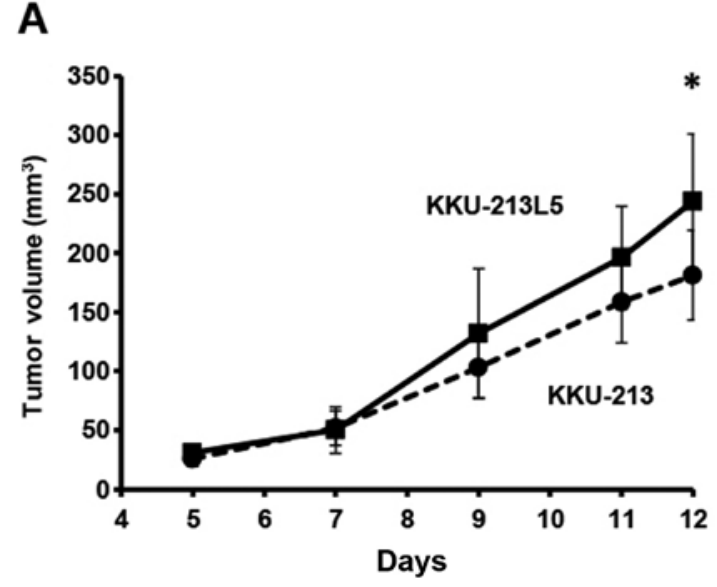

B
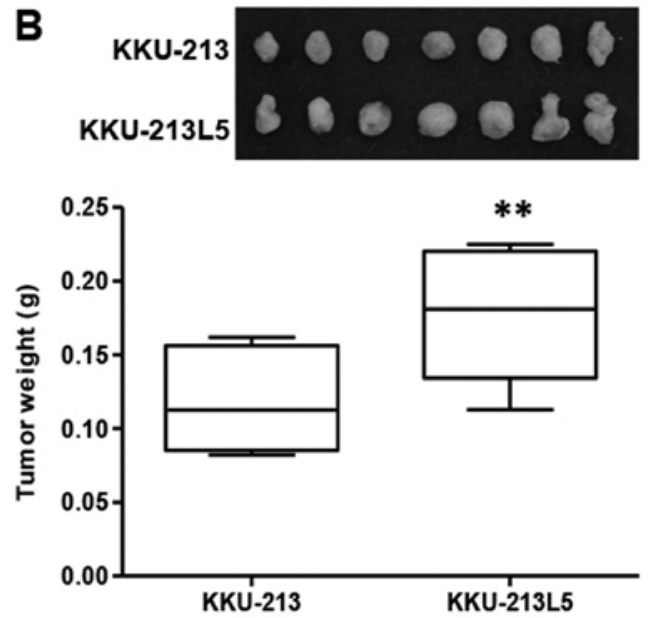

Figure 3. Tumor growth in vivo. Cells from the KKU-213 and KKU-213L5 cell lines were subcutaneously injected in BALB/c Rag- $2^{-/ /} / \mathrm{Jak}^{-/-}$mice (n=8). (A) Tumor volume and (B) weight with tumor masses in small insets are shown after 12 days. The data are mean $\pm \mathrm{SD}$. ${ }^{*} \mathrm{P}<0.05$, ${ }^{* *} \mathrm{P}<0.01$.

CSCs in KKU-213L5. Six CSC markers (CD29, CD34, CD44, CD90, CD117 and CD133) from common liver stem cell markers (15) were investigated in the parental KKU-213 and highly metastatic KKU-213L5 cells. Only 3 markers; CD29, CD44 and CD133, were expressed on the surface of these CCA cells and only CD44 and CD133 were differentially expressed (Fig. 1D). As compared to KKU-213, the expression of $\mathrm{CD} 133$ was increased $(1.9 \pm 0.3$ vs. $0.7 \pm 0.5 ; \mathrm{P}<0.05)$ whereas that of CD44 was decreased $(74.5 \pm 9.3$ vs. $94.7 \pm 5.2 ; \mathrm{P}<0.05)$ in the KKU-213L5 cells.

Properties of the highly metastatic subline KKU-213L5 in vivo

Tumorigenicity. Both KKU-213 and KKU-213L5 cells were tumorigenic as the sizes of inoculums were progressively increased and reached sizes of 0.1-0.25 g within 12 days. The tumor growths of the KKU-213L5 subline, however, exceeded those of the parental KKU-213 cells both in tumor volume (Fig. 3A) and tumor weight (Fig. 3B). At 12 days postinoculation, the average tumor weight of the KKU-213L5 cells $(0.18 \pm 0.04 \mathrm{~g})$ was significantly higher than that of the parental KKU-213 cells $(0.11 \pm 0.03 \mathrm{~g} ; \mathrm{P}<0.01)$. Distant organ metastases, e.g., lung and liver were not observed in this period of time.

Metastatic activity. The aggressiveness of the metastatic KKU-213L5 cells over the parental cells was determined by the percent survival of the mice after tail-vein injection (Fig. 4A). Mice injected with KKU-213L5 had shorter survival with a median survival of 21 days compared to 36 days of the parental cell group (log-rank; $\mathrm{P}<0.0001)$. The KKU-213L5 cells developed lung metastases with high efficiency in the animal model. After 13 and 21 days post intravenous injection, the CCA cells that were colonized in the lungs were examined using cytokeratin-19 (CK19) immunohistochemistry (Fig. 4B). KKU-213L5-injected mice significantly developed numerous lung colonizations with micrometastatic and macrometastatic foci within 13 days of injection, whereas the metastatic foci were hardly detected in the KKU-213 cell group (Fig. 4C; $\mathrm{P}<0.001$ ). Macrometastases were observed from the KKU-213 cells at 21 days postinjection but the number was considerably fewer than those observed for the KKU-213L5 cells $(\mathrm{P}<0.05)$.

Identification of metastasis-related genes in KKU-213L5. Cancer metastasis is a complicated process supported by abnormal expression of metastasis-associated genes. To understand the molecular mechanisms supporting the highly metastatic activities of KKU-213L5, differential expression levels of 77 metastatic-associated genes regarding cell proliferation, cell migration and cell invasion (Table I) were determined in the KKU-213L5 cells in comparison with the KKU-213 cells using real-time PCR.

To increase the chance for uncovering the metastatic-associated genes, the expression levels of genes that were $>1.2$-fold different were designated as upregulated and those $<0.5$-fold were designated as downregulated. Cluster analysis (dChip) of the metastatic-associated genes revealed 21 differentially expressed genes in KKU-213L5 with 7 upregulated and 14 downregulated. AGR2, KRT13, EREG and FN1 were upregulated with a >2-fold difference; whereas JAG1, ANXA1 and EGFR3 had a $>1.2$-fold difference. In contrast, KiSS-1, IFI27, VIM, CDH2 and PXN were downregulated with a $<0.5$-fold difference (Fig. 5; Table II). Using STRING9.1 (http://string-db.org), these differentially expressed genes were suggested to be involved in wound healing and cellular component movement.

Expression levels of AGR2 and KiSS-1 are associated with metastatic potential of KKU-213L5 cells. As shown in Fig. 5, AGR2 was in the first rank of upregulated genes and KiSS-1, a metastasis suppressor was in the first rank of downregulated genes found in the KKU-213L5 cells when compared to those of the parental KKU-213 cells. To validate the association of these two genes in the metastasis of CCA, the expression levels of AGR2 and KiSS-1 were confirmed in clinical specimens from CCA patients with different metastatic statuses. Paraffinembedded tumor tissues from histologically confirmed 

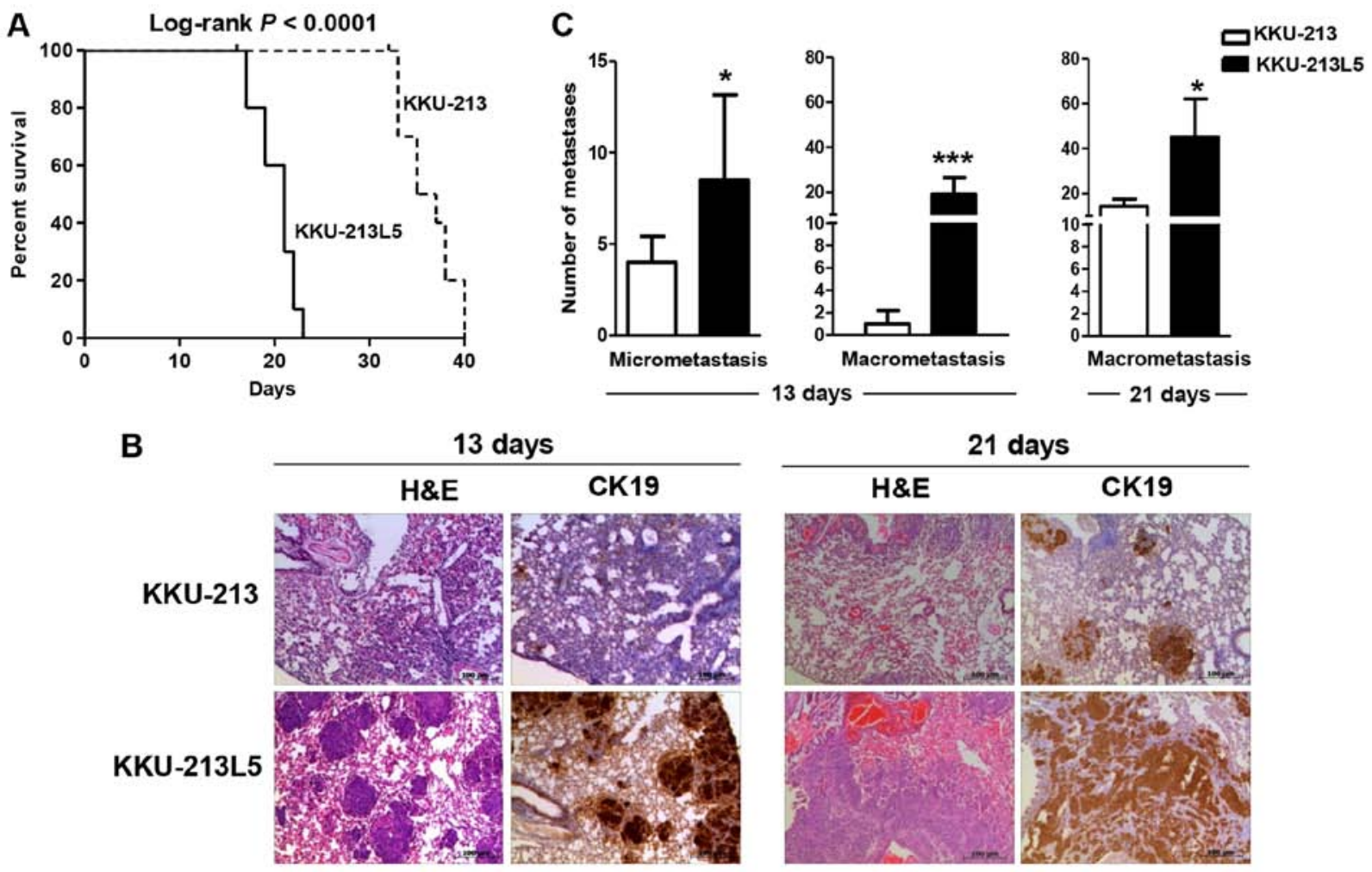

Figure 4. Tumor metastasis in vivo. Cells from the KKU-213 and KKU-213L5 cell lines were intravenously inoculated into NOJ mice via the tail vein. Lungs were collected at 13 and 21 days post-injection, and pulmonary micrometastases and macrometastases were counted. (A) Percent survival, (B) histological features of the lung metastatic nodules observed at days 13 and 21, and (C) the numbers of micrometastases and macrometastases obtained at days 13 and 21 post-injection were determined. Data represent mean $\pm \mathrm{SD}$ of metastases for each group. Scale bar, $100 \mu \mathrm{m} ;{ }^{*} \mathrm{P}<0.05,{ }^{* * * *} \mathrm{P}<0.001$.

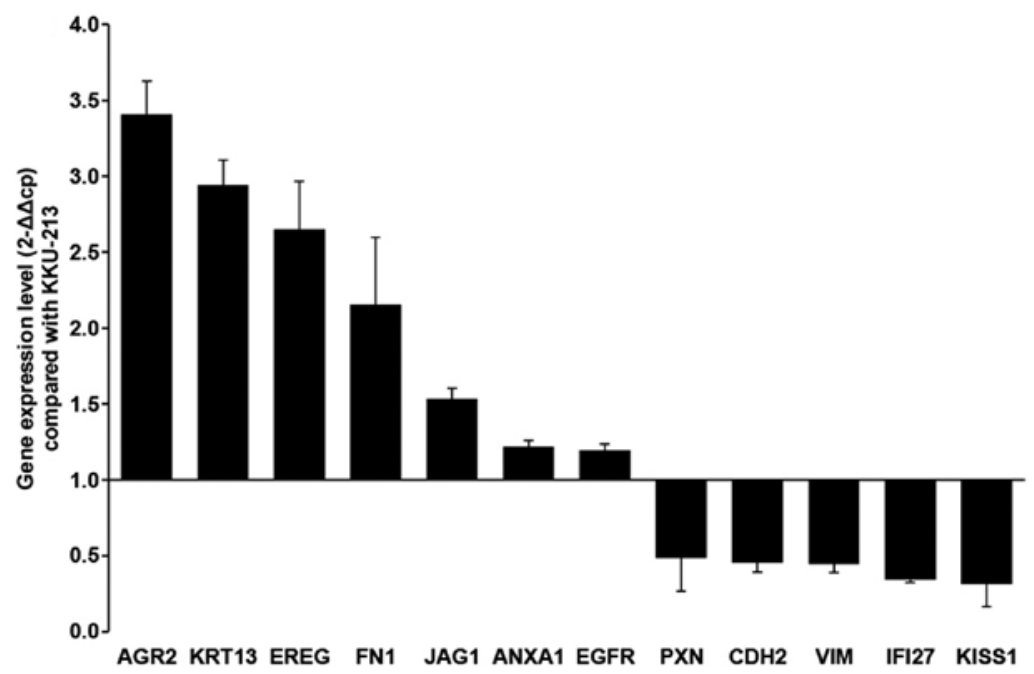

Figure 5. Differential expression of genes in the KKU-213L5 cells. Expression levels of 77 metastatic-associated genes were determined in the KKU-213L5 cells in comparison with the parental KKU-213 cells using real-time PCR. Genes that were upregulated $>1.2$-fold and downregulated $<0.5$-fold in the KKU-213L5 cells are shown.

intrahepatic CCA patients with different tumor staging $(n=32)$ were examined for AGR2 and KiSS-1 immunohistochemical analysis. Normal bile duct epithelia from the adjacent non-tumorous tissues were assessed. Normal bile ducts occasionally expressed AGR2, however, it was frequently found in CCA tissues with strong intensity. The expression of AGR2 was significantly higher in the CCA tissues than that in the normal bile ducts (Fig. 6A and B) $(\mathrm{P}<0.001)$. Moreover, AGR2 expression was gradually increased with higher stages of tumor development. Expression of AGR2 in the CCA tissues of stage IVB was significantly higher than these levels in stages IVA and III $(\mathrm{P}<0.05)$. In contrast to AGR2, KiSS-1 was strongly expressed in normal bile ducts and gradually decreased with increasing tumor stages (Fig. 6A and $\mathrm{B})(\mathrm{P}<0.05)$. 
Table I. List of 77 genes selected for the metastatic PCR array.

\begin{tabular}{|c|c|c|c|}
\hline No. & Gene symbol & Gene name & Accession no. \\
\hline 1 & ACTN1 & Actinin, $\alpha 1$ & NM_001102.3 \\
\hline 2 & AGR2 & Anterior gradient 2 homolog (Xenopus laevis) & NM_006408.3 \\
\hline 3 & AKT1 & v-akt murine thymoma viral oncogene homolog 1 & NM_001014431.1 \\
\hline 4 & ANXA1 & Annexin A1 & NM_000700.1 \\
\hline 5 & BSG & Basigin (OK blood group) & NM_001728.3 \\
\hline 6 & CAV1 & Caveolin 1 & NM_001172895.1 \\
\hline 7 & CCND2 & Cyclin D2 & NM_001759.3 \\
\hline 8 & CCNE2 & Cyclin E2 & NM_057749.2 \\
\hline 9 & CD44 & CD44 molecule (Indian blood group) & NM_000610.3 \\
\hline 10 & CD82 & CD82 molecule & NM_001024844.1 \\
\hline 11 & CDH1 & Cadherin 1, type 1, E-cadherin (epithelial) & NM_004360.3 \\
\hline 12 & $\mathrm{CDH} 2$ & Cadherin 2, type 1, N-cadherin (neuronal) & NM_001792.3 \\
\hline 13 & CFL1 & Cofilin 1 (non-muscle) & NM_005507.2 \\
\hline 14 & CLDN4 & Claudin 4 & NM_001305.3 \\
\hline 15 & CLDN7 & Claudin 7 & NM_001185022.1 \\
\hline 16 & CST7 & Cystatin F (leukocystatin) & NM_003650.3 \\
\hline 17 & CTBP1 & C-terminal binding protein 1 & NM_001012614.1 \\
\hline 18 & CTNNB1 & Catenin (cadherin-associated protein), $\beta 1$ & NM_001904.3 \\
\hline 19 & DSP & Desmoplakin & NM_001008844.1 \\
\hline 20 & EGFR & Epidermal growth factor receptor & NM_005228.3 \\
\hline 21 & EPCAM & Epithelial cell adhesion molecule & NM_002354.2 \\
\hline 22 & ERBB3 & $\begin{array}{l}\text { v-erb-b2 erythroblastic leukemia viral oncogene } \\
\text { Homolog } 3 \text { (avian) }\end{array}$ & NM_001005915.1 \\
\hline 23 & EREG & Epiregulin & NM_001432.2 \\
\hline 24 & FLT4 & fms-related tyrosine kinase 4 & NM_002020.4 \\
\hline 25 & FN1 & Fibronectin 1 & NM_002026.2 \\
\hline 26 & FOXC1 & Forkhead box $\mathrm{C} 1$ & NM_001453.2 \\
\hline 27 & GAPDH & Glyceraldehyde-3-phosphate dehydrogenase & NM_002046.4 \\
\hline 28 & $\mathrm{HOXB7}$ & Homeobox B7 & NM_004502.3 \\
\hline 29 & HSPB2 & Heat shock $27 \mathrm{kDa}$ protein 2 & NM_001541.3 \\
\hline 30 & ICAM1 & Intercellular adhesion molecule 1 & NM_000201.2 \\
\hline 31 & IFI27 & Interferon, $\alpha$-inducible protein 27 & NM_001130080.1 \\
\hline 32 & ILK & Integrin-linked kinase & NM_001014794.1 \\
\hline 33 & ITGA5 & Integrin, $\alpha 5$ & NM_002205.2 \\
\hline 34 & ITGB1 & Integrin, $\beta 1$ & NM_002211.3 \\
\hline 35 & JAG1 & Jagged 1 & NM_000214.2 \\
\hline 36 & KISS1 & KiSS-1 metastasis-suppressor & NM_002256.3 \\
\hline 37 & KRT13 & Keratin 13 & NM_002274.3 \\
\hline 38 & LDHA & Lactate dehydrogenase A & NM_005566.3 \\
\hline 39 & METAP2 & Methionyl aminopeptidase 2 & NM_006838.3 \\
\hline 40 & MMP3 & Matrix metallopeptidase 3 (stromelysin 1, progelatinase) & NM_002422.3 \\
\hline 41 & MMP7 & Matrix metallopeptidase 7 (matrilysin, uterine) & NM_002423.3 \\
\hline 42 & MMP9 & $\begin{array}{l}\text { Matrix metallopeptidase } 9 \text { (gelatinase B, } 92 \mathrm{kDa} \text { gelatinase, } \\
92 \mathrm{kDa} \text { type IV collagenase) }\end{array}$ & NM_004994.2 \\
\hline 43 & MSN & Moesin & NM_002444.2 \\
\hline 44 & NF2 & Neurofibromin 2 (merlin) & NM_000268.3 \\
\hline 45 & NME1 & NME/NM23 nucleoside diphosphate kinase 1 & NM_000269.2 \\
\hline 46 & OCLN & Occludin & NM_001205254.1 \\
\hline 47 & PGK1 & Phosphoglycerate kinase 1 & NM_000291.3 \\
\hline 48 & PLAUR & Plasminogen activator, urokinase receptor & NM_001005376.2 \\
\hline 49 & PTEN & Phosphatase and tensin homolog & NM_000314.4 \\
\hline 50 & PTK2 & Protein tyrosine kinase 2 & NM_001199649.1 \\
\hline
\end{tabular}


Table I. Continued.

\begin{tabular}{|c|c|c|c|}
\hline No. & Gene symbol & Gene name & Accession no. \\
\hline 51 & PXN & Paxillin & NM_001080855.2 \\
\hline 52 & RAC1 & $\begin{array}{l}\text { Ras-related C3 botulinumtoxin substrate } 1 \\
\text { (Rho family, small GTP binding protein Rac1) }\end{array}$ & NM_006908.4 \\
\hline 53 & RAC2 & $\begin{array}{l}\text { Ras-related C3 botulinumtoxin substrate } 2 \\
\text { (Rho family, small GTP binding protein Rac2) }\end{array}$ & NM_002872.3 \\
\hline 54 & REG1A & Regenerating islet-derived $1 \alpha$ & NM_002909.4 \\
\hline 55 & RHO & Rhodopsin & NM_000539.3 \\
\hline 56 & RHOA & Ras homolog family member A & NM_001664.2 \\
\hline 57 & RHOB & Ras homolog family member B & NM_004040.2 \\
\hline 58 & RHOC & Ras homolog family member $\mathrm{C}$ & NM_001042678.1 \\
\hline 59 & ROCK1 & Rho-associated, coiled-coil containing protein kinase 1 & NM_005406.2 \\
\hline 60 & S100P & S100 calcium binding protein $P$ & NM_005980.2 \\
\hline 61 & SERPINE1 & $\begin{array}{l}\text { Serpin peptidase inhibitor, clade } \mathrm{E} \\
\text { (nexin, plasminogen activator inhibitor type } 1 \text { ), member } 1\end{array}$ & NM_000602.4 \\
\hline 62 & SNAI1 & Snail family zinc finger 1 & NM_005985.3 \\
\hline 63 & SNAI2 & Snail family zinc finger 2 & NM_003068.4 \\
\hline 64 & SPP1 & Secreted phosphoprotein 1 & NM_001251830 \\
\hline 65 & STAT3 & $\begin{array}{l}\text { Signal transducer and activator of transcription } 3 \\
\text { (acute-phase response factor) }\end{array}$ & NM_003150.3 \\
\hline 66 & TACSTD2 & Tumor-associated calcium signal transducer 2 & NM_002353.2 \\
\hline 67 & TGFB1 & Transforming growth factor, $\beta 1$ & NM_000660.4 \\
\hline 68 & TIMP1 & TIMP metallopeptidase inhibitor 1 & NM_003254.2 \\
\hline 69 & TIMP2 & TIMP metallopeptidase inhibitor 2 & NM_003255.4 \\
\hline 70 & TM4SF1 & Transmembrane 4 L six family member 1 & NM_014220.2 \\
\hline 71 & TOB1 & Transducer of ERBB2, 1 & NM_005749 \\
\hline 72. & TWIST1 & Twist basic helix-loop-helix transcription factor 1 & NM_000474.3 \\
\hline 73 & VCAN & Versican & NM_004385 \\
\hline 74 & VCL & Vinculin & NM_003373.3 \\
\hline 75 & VEGFA & Vascular endothelial growth factor A & NM_001025366.2 \\
\hline 76 & VIM & Vimentin & NM_003380.3 \\
\hline 77 & ZEB1 & Zinc finger E-box binding homeobox 1 & NM_001128128.2 \\
\hline
\end{tabular}

Table II. Upregulated and downregulated genes in the KKU-213L5 cells compared with the KKU-213 cells.

\begin{tabular}{|c|c|c|c|c|}
\hline No. & Gene symbol & Gene name & Fold-change & P-value \\
\hline \multicolumn{5}{|c|}{ Upregulated genes } \\
\hline 1 & AGR2 & Anterior gradient 2 homolog (Xenopus laevis) & 3.41 & $1.00 \mathrm{E}-08$ \\
\hline 2 & KRT13 & Keratin 13 & 2.94 & $1.60 \mathrm{E}-07$ \\
\hline 3 & EREG & Epiregulin & 2.65 & $2.75 \mathrm{E}-06$ \\
\hline 4 & FN1 & Fibronectin 1 & 2.15 & $3.72 \mathrm{E}-02$ \\
\hline 5 & JAG1 & Jagged 1 & 1.53 & $4.59 \mathrm{E}-03$ \\
\hline 6 & ANXA1 & Annexin A1 & 1.22 & $3.34 \mathrm{E}-05$ \\
\hline 7 & EGFR & Epidermal growth factor receptor & 1.20 & $1.92 \mathrm{E}-03$ \\
\hline \multicolumn{5}{|c|}{ Downregulated genes } \\
\hline 1 & KISS1 & KiSS-1 metastasis-suppressor & 0.31 & $3.30 \mathrm{E}-02$ \\
\hline 2 & IFI27 & Interferon, $\alpha$-inducible protein 27 & 0.34 & $9.21 \mathrm{E}-06$ \\
\hline 3 & VIM & Vimentin & 0.45 & $4.85 \mathrm{E}-06$ \\
\hline 4 & $\mathrm{CDH} 2$ & Cadherin 2 , type $1, \mathrm{~N}$-cadherin (neuronal) & 0.46 & $5.45 \mathrm{E}-03$ \\
\hline 5 & PXN & Paxillin & 0.49 & 7.97E-03 \\
\hline
\end{tabular}


A
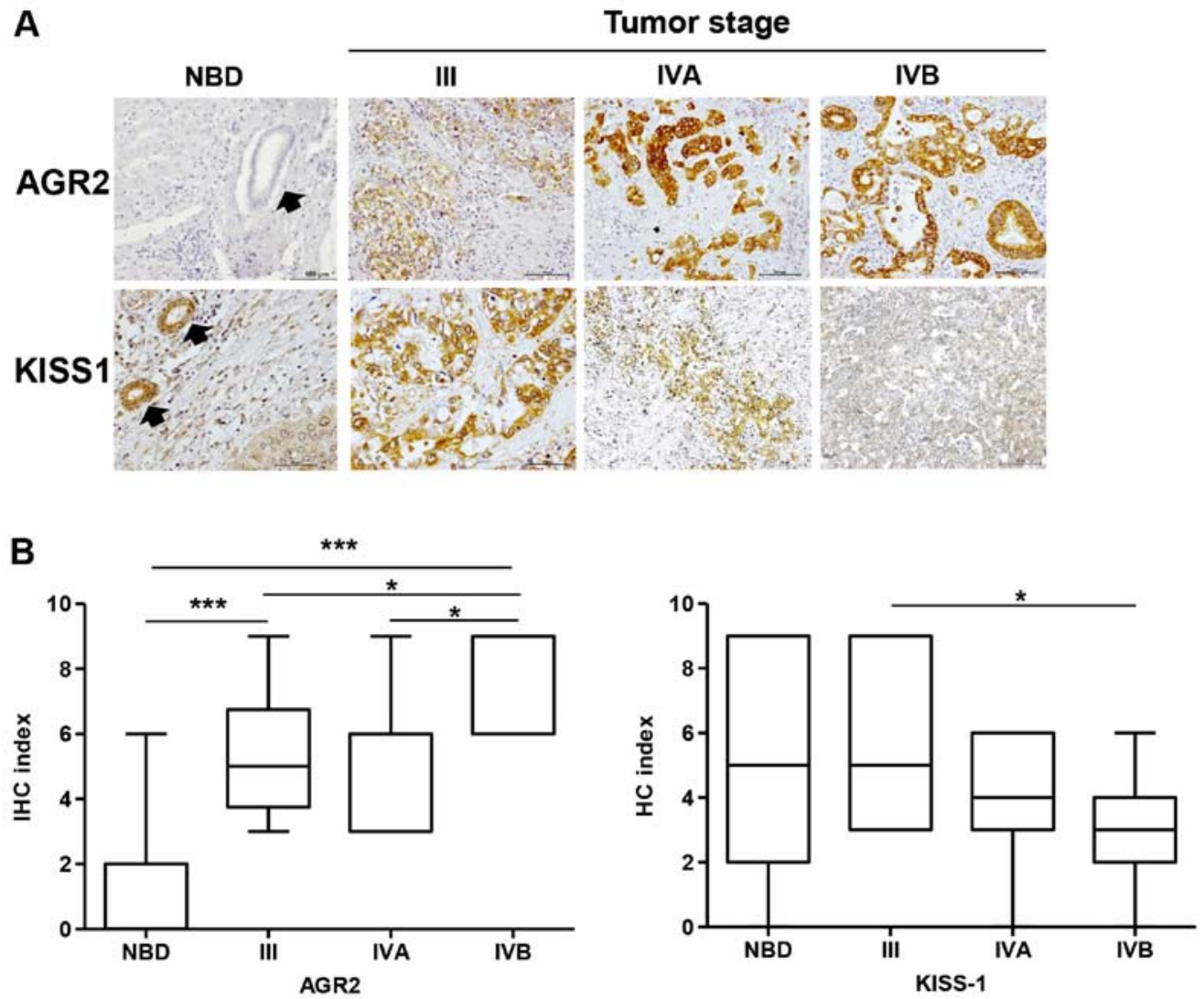

Figure 6. AGR2 and KiSS-1 expression in CCA patient tissues. Immunohistochemistry of AGR2 and KiSS-1 was performed in 32 cases of intrahepatic mass-forming CCA patient tissues with different tumor staging (A). The immunohistochemical (IHC) indices were determined in normal bile duct (NBD, $n=30)$, CCA stage III $(n=10)$, CCA stage IVA $(n=11)$ and CCA stage IVB $(n=11)$. Normal bile duct epithelia from adjacent non-tumorous tissues were assessed. Semi-quantitative analysis of AGR2 and KiSS-1 expression levels presented as IHC indices are shown in $(\mathrm{B}) ;{ }^{*} \mathrm{P}<0.05,{ }^{* * * *} \mathrm{P}<0.001$.

\section{Discussion}

Metastasis is the major cause of cancer morbidity and mortality. The complex nature of metastasis dictates the necessity for experimental systems that more closely simulate endogenous contributing factors. In the present study, we report the establishment and comparative characterization of a novel highly metastatic subline, designated KKU-213L5 and its parental, KKU-213 cell line. The cell lines were compared in vitro for cell proliferation, stem cell markers, migratory and invasive abilities. The xenografted and tail vein metastatic mouse models were used to compare tumorigenicity and lung metastatic capability. Furthermore, AGR2 and KiSS-1 were first identified and shown to be associated with the metastatic status of the CCA patients.

The present search from 1985-2016 revealed that there were 21 CCA established cell lines from 16 reports, 3 of which were established from Thai CCA patients which were assumed to be associated with liver fluke infections: HuCCA-1 (16), KKU-100 (8) and RMCCA-1 (17). Similar to other solid tumors, CCA is characterized as a highly metastatic cancer, and the lung is the common site for metastasis (18). A greater understanding of the biology of pulmonary metastases is needed to improve treatment outcomes. There are several models of highly metastatic cell lines established in the mouse with varied advantages and disadvantages to each. The present study used the tail-vein metastasis model which involves the injection of tumor cells via tail vein and analysis of their ability to form tumors and/or to colonize at distant sites e.g. lung via hematogenous spread. This model generates lung colonization of CCA without other distant colonization sites. The pitfall of this assay is the lack of measurement of the earlier invasive and angiogenic stages of malignant progression, and therefore may be an incomplete measure of the metastatic process.

Cell morphology of the KKU-213L5 cells was not obviously different from that of the parental cells, however, the KKU-213L5 cells demonstrated a significant increased rate of proliferation, migration and invasion compared to the KKU-213 cells. LM8, a lung metastatic osteosarcoma cell line, obtained from murine Dunn osteosarcoma using a similar mouse protocol also had a higher growth rate than its parental cell line (19). Higher growth rate, migration and invasion than the parental cells seem to be distinct characteristics of highly metastatic cells as shown in the present study and previous studies (19-22). As it is well-known, cancer stem cells which represent a relatively tiny portion of the tumor are responsible for building a cancer mass and enhancing metastatic potential (14). In the present study, cells that possessed the surface stem cell markers were enriched in the KKU-213L 5 cells containing considerably more of an apparent CD133-positive subpopulation than the KKU-213 cells. The association of a subgroup of hepatocellular carcinoma cells with $\mathrm{CD} 133^{+} \mathrm{CD} 44^{+}$and hematogenous metastasis was reported (23). In addition, the correlation of high CD133 
expression in CCA patient tissues with poor prognosis, with the tubular subtype, a higher tumor stage (T4), and shorter survival of these Thai CCA patients was previously reported (24). It is worth noting that the expression of CD44 appeared to be lower in the KKU-213L5 cells. CD44 is a pleomorphic protein and it has been shown that only specific variants of CD44 promote tumorigenesis (25). Altogether, these data support the hypothesis that the CSC population may confer higher metastatic activities to KKU-213L5.

The aggressiveness of the KKU-213L5 and KKU-213 cells was also demonstrated in the in vivo mouse models. The tumorigenicity and metastatic potential of KKU-213L5 were significantly higher than those of the KKU-213 cells as shown in the subcutaneous xenografted and tail-vein metastatic mouse models. The greater aggressiveness of KKU-213L5 was more obvious in the metastatic mouse model, by the fact that spontaneous pulmonary metastasis was significantly observed by determining KKU-213L5 > KKU-213. A few micrometastases were detected in the KKU-213 group 13 days post-injection, whereas at the same time period, a greater number of micrometastasis and macrometastasis (x20-fold) were found in lung tissues of the KKU-213L5-injected mice. The greater pulmonary metastasis of the KKU-213L5 group may be the cause of the significantly shorter survival in all KKU-213L5-injected mice when compared with the KKU-213-injected mice.

Metastasis requires functionally distinct sets of genes that provide metastatic initiation and progression. Cell migration and invasion are essential for early events in the metastatic process $(26,27)$; therefore, attention was focused on a small group of potentially important genes related to cell motility and invasion. The differential expression of 77 selected genes analyzed between KKU-213L5 and KKU-213 revealed significant upregulation of AGR2 and downregulation of KiSS-1. These two genes exhibited the highest differential expression levels between the two cell lines and have never been previously described in CCA metastasis. Since the differences in the expression may or may not account for the highly metastatic potential of KKU-213L5 cells, AGR2 and KiSS-1 were further investigated for their association with metastasis in CCA patient tissues.

The metastasis-associated genes retrieved from the KKU-213L5 cells can reflect the metastasis involvement of these genes in CCA patients. The expression levels of AGR2 and KiSS-1 were verified in CCA patient tissues using immunohistochemistry. The potential relevance of AGR2 and KiSS-1 in metastasis of intrahepatic mass-forming CCA is suggested. AGR2 was rarely expressed in normal bile duct epithelia, but was increased gradually according to the progression of the metastatic stage. The significant increase in AGR2 expression and concomitant tumor stage progression may imply the association of AGR2 in the metastasis of CCA.

AGR2 belongs to a family of protein disulfide isomerases (PDIs). The secreted form of AGR2 has been shown to function at the cell surface and the extracellular matrix $(28,29)$. Overexpression of AGR2 has been reported in various types of cancers and has been intensively studied in breast cancer. Overexpression of AGR2 was found to be related to the increase in cell survival and proliferation, whereas loss of AGR2 leads to a decrease in cell cycle progression and cell death (30-32).
In addition, AGR2 was shown to promote metastasis of breast epithelial cells in an in vivo metastasis assay (33) and the secreted AGR2 plays roles in cellular adhesion and dissemination of metastatic tumor cells (34). Therefore, inhibition of AGR2 was suggested to be useful in the targeted therapy of breast cancer.

There are only two previous studies on AGR2 in CCA. The expression of AGR2 in normal bile duct epithelia and CCA from these studies is still controversial. Lepreux et al (35) observed AGR2 only in the peribiliary glands and the tall epithelial cells of hilar large bile ducts, while Kim et al (36) found general expression of AGR2 in the epithelia of intrahepatic and extrahepatic biliary tracts. Moreover, from Lepreux's study, only $21 \%$ (3/14) of intrahepatic CCA expressed AGR2, whereas those from Kim's study, 82\% (9/11) were positive for AGR2. In the present study, upregulation of AGR2 expression in highly metastatic CCA cells and tissues was noted. Expression of AGR2 in advanced stage CCA was higher than that of earlier stage CCA. The discrepancy of AGR2 expression in CCA is varied among different study cohorts. Determination of AGR2 expression in association with clinicopathological information of patients in a larger sample size should be carefully conducted.

KiSS-1 is a member of the metastatic suppressors which can block metastasis without preventing primary tumor development. KiSS-1 effectively inhibits colonization of tumor cells, the last step of the metastatic cascade. Until the present search, there is no report on KiSS-1 in CCA. The role of KiSS-1 as a metastatic suppressor in CCA is emphasized in the present study by the fact that KiSS-1 expression was downregulated in the highly metastatic KKU-213L5 cells and was also decreased in the advanced stage CCA patient tissues. This observation agreed with clinical observations from various cancer patients. Immunohistochemistry studies of KiSS-1 in ovarian cancer revealed that the positivity of KiSS-1 was individually correlated with favorable prognosis and superior overall survival $(37,38)$. Low KiSS-1 expression was found to be correlated with metastases and poor survival of patients with gastrointestinal $(39,40)$ and pancreatic cancers $(41,42)$. In contrast, the antimetastatic role of KiSS-1 in breast cancer is still controversial. Loss of KiSS-1 expression was found to be related to positive lymph nodes in breast adenocarcinomas (43) and brain metastases (44). Moreover, patients with high KiSS-1 expression exhibited shorter disease-free survival (45).

In conclusion, understanding the molecular mechanisms of CCA progression and metastasis is essential for improving the prevention and ensuring the effective control of the metastasis of CCA. To the best of our knowledge, KKU-213L5 is the first CCA cell line with relatively high metastatic activity, not only in vitro but also in vivo. The metastasis-associated genes retrieved from KKU-213L5 can reflect the metastasis involvement of these genes in CCA patients. It is likely that differential expression of genes between the parental KKU-213 and the highly metastatic KKU-213L5 cells may be valuable to discover novel genes that control metastasis. This cell line will be an excellent tool for further dissection of the molecular mechanisms underlying the metastasis of CCA as well as an appropriate model for studying inhibitory agents against metastasis and the treatment of CCA. 


\section{Acknowledgements}

The present study was co-supported by Joint Research Grants from Khon Kaen University, the TRF Senior Research Scholar Grant, Thailand Research Fund to S.W. (RTA5780012), the Higher Education Research Promotion and National Research University Project of Thailand, Office of the Higher Education Commission, through the Health Cluster to S.W. (NRU58-2014), the Khon Kaen University Research Fund to K.V. (KKU59-2403), the Joint Funding through Royal Golden Jubilee Ph.D. Program and Khon Kaen University to K.U. and S.W. (PHD/0211/2550), and Japan Student Services Organization to K.U. and S.O. We would like to acknowledge Professor James A. Will for editing the manuscript via Publication Clinic KKU, Thailand.

\section{References}

1. Fidler IJ: The pathogenesis of cancer metastasis: The 'seed and soil' hypothesis revisited. Nat Rev Cancer 3: 453-458, 2003.

2. Paget S: The distribution of secondary growths in cancer of the breast. 1889. Cancer Metastasis Rev 8: 98-101, 1989.

3. Wakahara T, Tsukamoto T, Kitamura S, Watanabe A, Tsujimura T, Nakamura Y, Toyokawa A, Onishi N, Hamabe Y, Mukai H, et al Metastatic colon cancer from intrahepatic cholangiocarcinoma. J Hepatobiliary Pancreat Surg 12: 415-418, 2005.

4. Yamamoto M, Takasaki K and Yoshikawa T: Lymph node metastasis in intrahepatic cholangiocarcinoma. Jpn J Clin Oncol 29: 147-150, 1999.

5. Kuroki T, Fukuda K, Tajima Y, Matsuzaki S, Kitajima T, Furui J and Kanematsu T: Parapapillary choledochoduodenal fistula associated with cholangiocarcinoma. J Hepatobiliary Pancreat Surg 12: 143-146, 2005.

6. Takahashi I, Nakamura Y, Suzuki Y, Mitsuhashi N, Niibe H and Osada J: Case report: Bone metastasis from cholangiocarcinoma showing unusual accumulation on bone scintigraphy and $67 \mathrm{Ga}$ scintigraphy. Br J Radiol 67: 303-305, 1994.

7. Li SQ, Liang LJ, Hua YP, Peng BG, He Q, Lu MD and Chen D: Long-term outcome and prognostic factors of intrahepatic cholangiocarcinoma. Chin Med J 122: 2286-2291, 2009.

8. Sripa B, Leungwattanawanit S, Nitta T, Wongkham C, Bhudhisawasdi V, Puapairoj A, Sripa C and Miwa M: Establishment and characterization of an opisthorchiasisassociated cholangiocarcinoma cell line (KKU-100). World J Gastroenterol 11: 3392-3397, 2005.

9. Okada S, Harada H, Ito T, Saito T and Suzu S: Early development of human hematopoietic and acquired immune systems in new born NOD/Scid/Jak3 $3^{\text {null }}$ mice intrahepatic engrafted with cord blood-derived CD34+ cells. Int J Hematol 88: 476-482, 2008.

10. Patterson MK Jr: Measurement of growth and viability of cells in culture. Methods Enzymol 58: 141-152, 1979.

11. Grenman R, Burk D, Virolainen E, Buick RN, Church J, Schwartz DR and Carey TE: Clonogenic cell assay for anchoragedependent squamous carcinoma cell lines using limiting dilution. Int J Cancer 44: 131-136, 1989.

12. Uthaisar K, Seubwai W, Srikoon P, Vaeteewoottacharn K, Sawanyawisuth K, Okada S and Wongkham S: Cepharanthine suppresses metastatic potential of human cholangiocarcinoma cell lines. Asian Pac J Cancer Prev 13 (Suppl): S149-S154, 2012.

13. Kan J, Thomson S, Argast GM, O'Connor ME, Robinson M, Feng B, Heyer J, Chiu MI and Nicoletti R: Use of EMT gene signatures in cancer drug discovery, diagnostics and treatment US Patent Application Publication. Pub. No.: US2012/0302572 $\mathrm{A} 1,2012$.

14. Li F, Tiede B, Massagué J and Kang Y: Beyond tumorigenesis: Cancer stem cells in metastasis. Cell Res 17: 3-14, 2007.

15. Mishra L, Banker T, Murray J, Byers S, Thenappan A, He AR, Shetty K, Johnson L and Reddy EP: Liver stem cells and hepatocellular carcinoma. Hepatology 49: 318-329, 2009.

16. Sirisinha S, Tengchaisri T, Boonpucknavig S, Prempracha N, Ratanarapee S and Pausawasdi A: Establishment and characterization of a cholangiocarcinoma cell line from a Thai patient with intrahepatic bile duct cancer. Asian Pac J Allergy Immunol 9: 153-157, 1991.
17. Rattanasinganchan $\mathrm{P}$, Leelawat $\mathrm{K}$, Treepongkaruna SA, Tocharoentanaphol C, Subwongcharoen S, Suthiphongchai T and Tohtong R: Establishment and characterization of a cholangiocarcinoma cell line (RMCCA-1) from a Thai patient. World J Gastroenterol 12: 6500-6506, 2006.

18. Goodman ZD, Terracciano LM and Wee A: 14 - Tumours and tumour-like lesions of the liver. In: MacSween's Pathology of the Liver. Burt AD, Portmann BC and Ferrell LD (eds). 6th edition. Churchill Livingstone, Edinburgh, pp761-851, 2012.

19. Asai T, Ueda T, Itoh K, Yoshioka K, Aoki Y, Mori S and Yoshikawa $\mathrm{H}$ : Establishment and characterization of a murine osteosarcoma cell line (LM8) with high metastatic potential to the lung. Int J Cancer 76: 418-422, 1998.

20. Li Y, Tang ZY, Ye SL, Liu YK, Chen J, Xue Q, Chen J, Gao DM and Bao WH: Establishment of cell clones with different metastatic potential from the metastatic hepatocellular carcinoma cell line MHCC97. World J Gastroenterol 7: 630-636, 2001.

21. Barroga EF, Kadosawa T, Okumura M and Fujinaga T: Establishment and characterization of the growth and pulmonary metastasis of a highly lung metastasizing cell line from canine osteosarcoma in nude mice. J Vet Med Sci 61: 361-367, 1999.

22. Su Y, Luo X, He BC, Wang Y, Chen L, Zuo GW, Liu B, Bi Y, Huang J, Zhu GH, et al: Establishment and characterization of a new highly metastatic human osteosarcoma cell line. Clin Exp Metastasis 26: 599-610, 2009.

23. Hou Y, Zou Q, Ge R, Shen F and Wang Y: The critical role of CD133 ${ }^{+} \mathrm{CD} 44^{+/ \text {high }}$ tumor cells in hematogenous metastasis of liver cancers. Cell Res 22: 259-272, 2012.

24. Thanan R, Pairojkul C, Pinlaor S, Khuntikeo N, Wongkham C, Sripa B, Ma N, Vaeteewoottacharn K, Furukawa A, Kobayashi H, et al: Inflammation-related DNA damage and expression of CD133 and Oct3/4 in cholangiocarcinoma patients with poor prognosis. Free Radic Biol Med 65: 1464-1472, 2013.

25. Guo W and Frenette PS: Alternative CD44 splicing in intestinal stem cells and tumorigenesis. Oncogene 33: 537-538, 2014.

26. Hajra KM and Fearon ER: Cadherin and catenin alterations in human cancer. Genes Chromosomes Cancer 34: 255-268, 2002.

27. Skubitz AP: Adhesion molecules. Cancer Treat Res 107: 305-329, 2002.

28. Adam PJ, Boyd R, Tyson KL, Fletcher GC, Stamps A, Hudson L, Poyser HR, Redpath N, Griffiths M, Steers G, et al:Comprehensive proteomic analysis of breast cancer cell membranes reveals unique proteins with potential roles in clinical cancer. J Biol Chem 278: 6482-6489, 2003.

29. Dumartin L, Whiteman HJ, Weeks ME, Hariharan D, Dmitrovic B, Iacobuzio-Donahue CA, Brentnall TA, Bronner MP, Feakins RM, Timms JF, et al: AGR2 is a novel surface antigen that promotes the dissemination of pancreatic cancer cells through regulation of cathepsins B and D. Cancer Res 71: 7091-7102,2011.

30. Vanderlaag KE, Hudak S, Bald L, Fayadat-Dilman L, Sathe M, Grein J and Janatpour MJ: Anterior gradient-2 plays a critical role in breast cancer cell growth and survival by modulating cyclin D1, estrogen receptor- $\alpha$ and survivin. Breast Cancer Res 12: R32, 2010.

31. Park K, Chung YJ, So H, Kim K, Park J, Oh M, Jo M, Choi K, Lee EJ, Choi YL, et al: AGR2, a mucinous ovarian cancer marker, promotes cell proliferation and migration. Exp Mol Med 43: 91-100, 2011.

32. Wang Z, Hao Y and Lowe AW: The adenocarcinoma-associated antigen, $A G R 2$, promotes tumor growth, cell migration, and cellular transformation. Cancer Res 68: 492-497, 2008.

33. Liu D, Rudland PS, Sibson DR, Platt-Higgins A and Barraclough R: Human homologue of cement gland protein, a novel metastasis inducer associated with breast carcinomas. Cancer Res 65: 3796-3805, 2005.

34. Chanda D, Lee JH, Sawant A, Hensel JA, Isayeva T, Reilly SD, Siegal GP, Smith C, Grizzle W, Singh R, et al: Anterior gradient protein-2 is a regulator of cellular adhesion in prostate cancer. PLoS One 9: e89940, 2014.

35. Lepreux S, Bioulac-Sage P and Chevet E: Differential expression of the anterior gradient protein-2 is a conserved feature during morphogenesis and carcinogenesis of the biliary tree. Liver Int 31: 322-328, 2011.

36. Kim SJ, Kim DH, Kang D and Kim JH: Expression of anterior gradient 2 is decreased with the progression of human biliary tract cancer. Tohoku J Exp Med 234: 83-88, 2014.

37. Hata K, Dhar DK, Watanabe Y, Nakai $\mathrm{H}$ and Hoshiai $\mathrm{H}$ : Expression of metastin and a G-protein-coupled receptor (AXOR12) in epithelial ovarian cancer. Eur J Cancer 43: 1452-1459, 2007. 
38. Prentice LM, Klausen C, Kalloger S, Köbel M, McKinney S, Santos JL, Kenney C, Mehl E, Gilks CB,Leung P, et al: Kisspeptin and GPR54 immunoreactivity in a cohort of 518 patients defines favourable prognosis and clear cell subtype in ovarian carcinoma. BMC Med 5: 33, 2007.

39. Dhar DK, Naora H, Kubota H, Maruyama R, Yoshimura H, Tonomoto Y, Tachibana M, Ono T, Otani H and Nagasue N: Downregulation of KiSS-1 expression is responsible for tumor invasion and worse prognosis in gastric carcinoma. Int $\mathbf{J}$ Cancer 111: 868-872, 2004.

40. Guan-Zhen Y, Ying C, Can-Rong N, Guo-Dong W, Jian-Xin Q and Jie-Jun W: Reduced protein expression of metastasis-related genes (nm23, KISS1, KAI1 and p53) in lymph node and liver metastases of gastric cancer. Int J Exp Pathol 88: 175-183, 2007.

41. Masui T, Doi R, Mori T, Toyoda E, Koizumi M, Kami K, Ito D, Peiper SC, Broach JR, Oishi S, et al: Metastin and its variant forms suppress migration of pancreatic cancer cells. Biochem Biophys Res Commun 315: 85-92, 2004.
42. Nagai K, Doi R, Katagiri F, Ito T, Kida A, Koizumi M, Masui T, Kawaguchi Y, Tomita K, Oishi S, et al: Prognostic value of metastin expression in human pancreatic cancer. J Exp Clin Cancer Res 28: 9, 2009.

43. Kostadima L, Pentheroudakis G and Pavlidis N: The missing kiss of life: Transcriptional activity of the metastasis suppressor gene KiSS1 in early breast cancer. Anticancer Res 27: 2499-2504, 2007.

44. Stark AM, Tongers K, Maass N, Mehdorn HM and Held-Feindt J: Reduced metastasis-suppressor gene mRNA-expression in breast cancer brain metastases. J Cancer Res Clin Oncol 131: 191-198, 2005.

45. Marot D, Bieche I, Aumas C, Esselin S, Bouquet C, Vacher S, Lazennec G, Perricaudet M, Kuttenn F, Lidereau R, et al: High tumoral levels of Kiss 1 and G-protein-coupled receptor 54 expression are correlated with poor prognosis of estrogen receptor-positive breast tumors. Endocr Relat Cancer 14: 691-702, 2007. 